\title{
SALUD MENTAL
}

\section{Estudio en tres familias de las consecuencias en la salud mental de sus miembros causados por pertenecer a la empresa familiar. Posibles estrategias de afrontamiento}

\author{
Atilio A. Aponte
}

Resumen

Introducción: El objetivo es estudiar la repercusión emocional que tiene en los miembros de una familia el hecho de trabajar en empresas familiares, y así contribuir a la salud mental de los involucrados, en nuestro país son bastante numerosas las empresas familiares, sin embargo, pocos estudios en nuestro país se plantean la problemática que surge en el interior de estas familias, los conflictos originados por el hecho de trabajar juntos y que los afectan de diferente manera.

En el año 2015, el representante del BID en el Paraguay presentó unas estadísticas en las que constataban que en nuestro país existen más de 700.000 empresas familiares y que estas empresas representan aproximadamente al $85 \%$ de las unidades económicas del país. Estas firmas producen el $65 \%$ de los bienes y servicios nacionales y generan el $66 \%$ de los empleos, por lo que la influencia de las empresas familiares en la economía del país es realmente considerable y produce un efecto multiplicador importante a nivel de empleos, debido a que en las empresas familiares no solamente trabajan personas del círculo familiar sino que además muchas que tienen una envergadura importante emplean también a una cantidad considerable de personas que no pertenecen a la familia, por lo tanto tienen un efecto multiplicador de dimensiones considerables. Debido a esto, las relaciones entre los directivos de la empresa familiar, sus condiciones emocionales, en síntesis, el estado de su salud mental, influye no solamente en su empresa, sino que influye indirectamente en la estabilidad laboral de muchas más personas a su alrededor.

Objetivo: Determinar cuáles son los efectos psicológicos en los miembros de una familia en la que sus integrantes trabajan en la empresa familiar. Reconocer la mecánica de las conductas que originan o son consecuencia de los efectos psicológicos afecta a la salud mental en la familia

Material y Método: Estudio cualitativo, de investigación-acción, en tres familias que poseen empresas familiares y en la que todos sus miembros

1. Universidad Iberoamericana. Facultad de Ciencias Humanísticas y de la Educación.

E-mail: atilio@maintec.com.py

DOI: 10.26885/rcei.foro.2018.152 
participan en la empresa de una $u$ otra manera, se ha considerado para este estudio numerosas variables y parámetros relativos a la jerarquía y la función, así como a la evolución, crecimiento y sucesión en las empresas familiares. Se ha tomado una empresa de servicios, una empresa educativa y una empresa industrial. La recolección de datos se ha hecho tanto in situ en las empresas, en los hogares familiares y a través de entrevistas, cuestionarios, observación y medidas de parámetros bio-fisiológicos, todos los datos han sido tomados o verificados por el autor. Las familias han sido debidamente informadas que el trabajo de intervención de salud emocional realizado en ellas se utilizaría para la presentación de una investigación científica.

Resultados: Las familias muestra de este estudio se componen por los progenitores fundadores de las empresas y la segunda generación, la de los hijos. Se ha detectado de manera fehaciente que ciertas conductas de unos y de otros afectan en grado sumo a la salud mental de los miembros de la familia, esto interesa fundamentalmente a la relación familiar como también al rendimiento de la empresa, durante el proceso se ha hecho intervenciones a nivel familiar y familiar/empresarial en todas ellas, por supuesto estas intervenciones han llegado hasta todos aquellos que participan de las funciones de la firma aunque no sean parte de la familia propietaria.

Conclusiones: Es importante para las familias que detectan conflictos que visiblemente afectan a la salud emocional de sus miembros debido a trabajar en la empresa familiar que tomen recaudos a tiempo e inclusive busquen prevenir las consecuencias emocionales de estos conflictos.

Palabras clave: mental, empresa, familiar.

\section{RefERENCIAS}

Avey, J. B, Avolio, J. B., Crossley, C. D. (2009). Psychological ownership: Theoretical extensions, measurement and relation to work outcomes. Journal of Organizational Behavior, 30(2), 173-191.

Gallo, M. A. (2008). Ideas básicas para dirigir la empresa familiar. Barañain: Ediciones Universidad de Navarra.

Lévi-Strauss, C. (1977). Antropología estructural. Buenos Aires: Editorial Universitaria de Buenos Aires, Eudeba.

Quejada Pérez, R. F., Nelson, J. (2016). Family-owned Companies: Definition, Theories and Structures. Rev. esc. adm. neg., (81), 149-158. 